\title{
INDUCTOR FOR CONTINUOUS HEATING IN HARDENING OF RAILWAY RAIL HEAD
}

\author{
E.A. PANTELEJMONOV and A.A. PISMENNY \\ E.O. Paton Electric Welding Institute, NASU \\ 11 Bozhenko Str., 03680, Kiev, Ukraine. E-mail: office@paton.kiev.ua
}

\begin{abstract}
Heat treatment of railway rails using HF current heating should be carried out considering the energy consumption for heating equipment service. The increase of efficiency of heat treatment process can be provided by improvement of the inductor design. The peculiarities of distribution of temperature field in the head of rail of R65 type at induction heating with current of $2.4 \mathrm{kHz}$ frequency under the conditions of stationary position of inductor relative to the rail were investigated. The models of inductors with different design of coils of inductive wire of magnetic core were used. It is shown that to achieve primary heating of rolling surface, as compared to side edges of the rail head, and to decrease the capacity of power source is possible by design of the inductor where windings of inductive wire are located across the rolling surface, along the rolling surface and along the lower part of side edges, and magnetic core embraces a part of windings of inductive wire over the rolling surface. The application of additional magnetic cores embracing the part of windings of inductive wire along the side edge of rail head, results in leveling of heating of a fillet, side edges and lower part of side edges. 6 Ref., 1 Table, 4 Figures.
\end{abstract}

$\boldsymbol{K} \boldsymbol{e} \boldsymbol{y} \boldsymbol{w} \boldsymbol{o} \boldsymbol{r} \boldsymbol{d} \boldsymbol{s}:$ rails, heat treatment of rails, induction HF current heating, inductors

The surface heat treatment (HT) of railway rail head with application of induction heating using HF currents is directed to improvement of physical and mechanical properties of rails and decrease of their stressed state. The concentration of energy in surface layer of metal, characteristic of $\mathrm{HF}$ current heating, provides high rates of heating across the thickness of head surface, allows controlling the level of dispersity of structure and size of austenite grain [1, 2]. At the same time HT with HF current heating is a sufficiently complex and power consuming process.

The HT technology of head of rails using continuously successive method in rail hardening machine (RHM) includes heating of rail head in three sections of inductors. After passing of the first and second sections of inductors the rail head is heated with considerable gradient of temperatures of surface and deep layers of metal. The exceeding in heating temperature of side edges is observed as compared to rolling surface. With the purpose of leveling the temperature field across the head section, the rail gets to the zone free from heating. The further heating of the rail head up to the preset temperature occurs in the third section of inductors. According to the requirements of technological instruction on production of railway rails of R65 type in RHM, HF current heating should provide the temperature at the head surface in range of $920-970{ }^{\circ} \mathrm{C}$ and depth of hardened layer of not less than $11 \mathrm{~mm}$. To reach such parameters of heating at the speed of movement of rails of $42-46 \mathrm{~mm} / \mathrm{s}$ and frequency of current of $2.4 \mathrm{kHz}$

(C) E.A. PANTELEJMONOV and A.A. PISMENNY, 2015 a total capacity of inductors of $1120-1220 \mathrm{~kW}$ is required $[3,4]$.

Under the conditions of high power capacity of HT with HF current heating the very urgent and important task is the decrease of power consumptions at operation of induction heating equipment. One of the ways of increasing its efficiency is improvement of design of inductors to attain the redistribution of temperature field in the rail head in the direction of primary heating of rolling surface as compared to side edges.

At the present work the influence of design of inductors on formation of temperature field in R65 rail head in stationary position of inductors relative to the rail was investigated. The inductors with different configuration of coils of inductive wire and magnetic cores were used.

In the design of inductor 1 (Figure 1,a) the coil of inductive wire repeats the shape and sizes of coils of inductors of the first and second sections of RHM. The coil of $\Pi$-shape consists of two windings of inductive wire, which embrace the rail head across the rolling surface and along the lower part of side edges of the head, closer to the rail neck. The instant direction of current in the windings of inductive wire is concordant. The length of coil along the rail head is $160 \mathrm{~mm}$. The size of air gap between the windings of inductive wire and rail head surface is $10 \mathrm{~mm}$. Magnetic core of plates of transformer steel of E-shape embraces windings of inductive wire in the places of their location across the rolling surface. Magnetic core is designed for increase of concentration of induced current under the windings of inductive wire and surface of head after the loss of the magnetic properties by the latter $[5,6]$. 

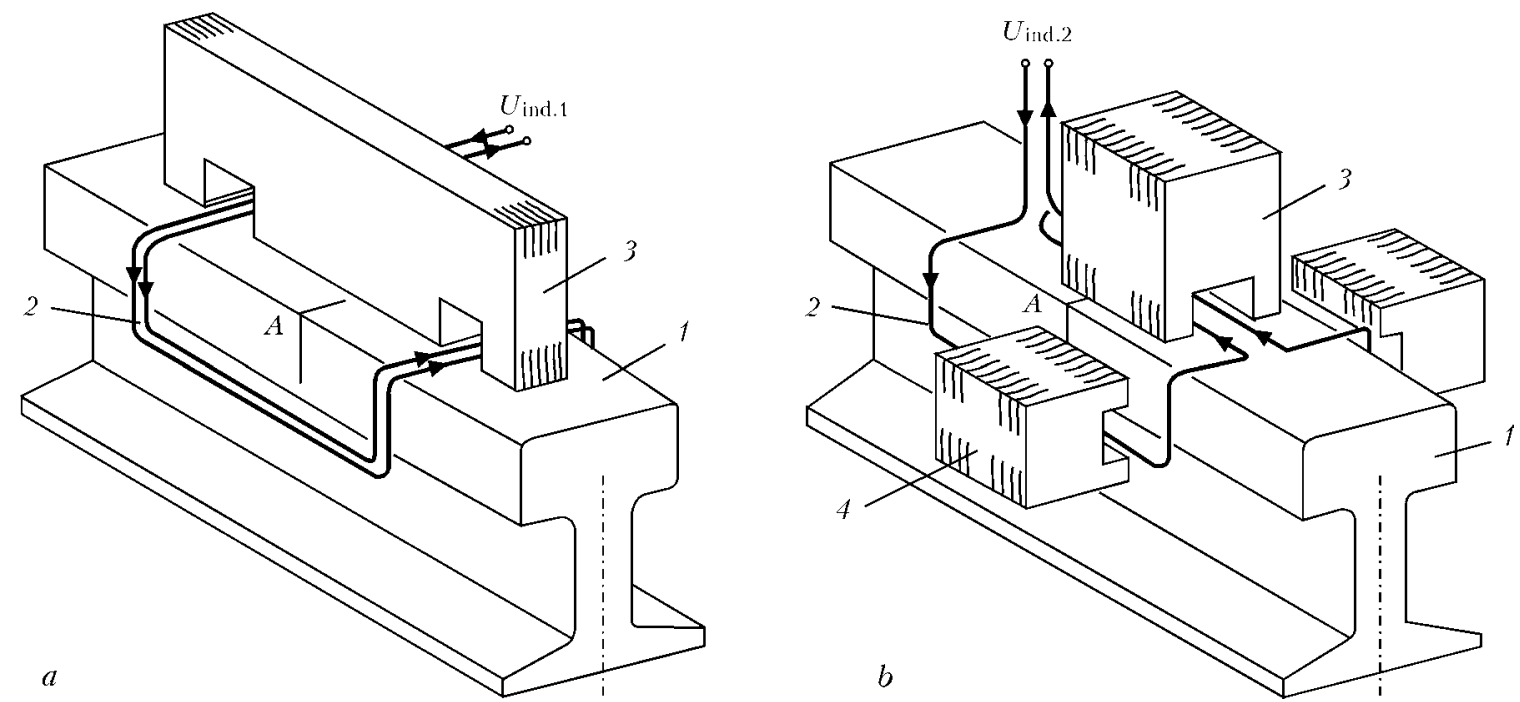

Figure 1. Design of inductors $1(a)$ and $2(b)$ for rail head heating: 1 - rail of R65 type; 2 - inductive wire; 3 main magnetic core; 4 - additional magnetic cores

The design of inductor 2 (Figure $1, b$ ) is characterized by that the part of windings of inductive wire is located along the rolling surface. The instant direction of current in this part of windings is concordant. The length of coil is $160 \mathrm{~mm}$, the size of air gap is $10 \mathrm{~mm}$. The main magnetic core embraces a part of windings of inductive wire over the rolling surface. Along the head side edges the additional magnetic cores installed. The plates of main and additional magnetic cores of П-shape are oriented across the rolling surface and across the side edges of rail head.

As a power source of inductors the thyristor frequency converter was applied connected according to the scheme to the matching transformer. The rated frequency of current was $2.4 \mathrm{kHz}$. For measurement of temperature of rail head heating the chromel-alumel thermal electric transducers were positioned in the points of cross section $A$ (see Figure 1), equidistant from edges of the coil of inductive wire along the length of the rail. The scheme of positioning of transducers is given in Figure 2.

The rail head heating was performed at the modes given in the Table. The capacity of power source in switching on of inductor 2 , as compared to inductor 1 , is lower, and coefficient of power is higher. The ratio of voltages and currents of

Electric parameters of modes of the rail head heating

\begin{tabular}{||l|c|c|c||}
\hline \multirow{2}{*}{ Parameter } & Inductor 1 & $\begin{array}{c}\text { Main } \\
\text { magnetic } \\
\text { core }\end{array}$ & $\begin{array}{c}\text { Main and } \\
\text { additional } \\
\text { magnetic } \\
\text { cores }\end{array}$ \\
\hline Power source capacity, kW & 44.8 & 36.4 & 27.5 \\
\hline Voltage of inductor $U_{\text {ind }}, \mathrm{V}$ & 56 & 26 & 26 \\
\hline $\begin{array}{l}\text { Current of inductor } I_{\text {ind }}, \\
\text { rel. un. }\end{array}$ & 4.5 & 3.0 & 2.3 \\
\hline $\begin{array}{l}\text { Power coefficient of induc- } \\
\text { tor cos } \varphi_{\text {ind }}\end{array}$ & 0.122 & 0.240 & 0.260 \\
\hline
\end{tabular}

inductors (Rogowski coil) is $U_{\text {ind.1 }}>U_{\text {ind.2 }}$ and $I_{\text {ind.1 }}>I_{\text {ind.2. }}$. The application of additional magnetic cores in the design of inductor 2 resulted in decrease of capacity of power source from 36.4 to $27.5 \mathrm{~kW}$ at the voltage $U_{\text {ind } .2}=26 \mathrm{~V}$.

The appropriate distribution of temperature field in the rail head is characterized by temporary dependencies of temperature in the points $1-6$ of the rail head, given in Figures 3 and 4. During switching on of inductor 1 (Figure $3, a$ ), the rate of heating of the lower part of side edges of rail head $\left(6.5^{\circ} \mathrm{C} / \mathrm{s}\right.$, points 5 and 6$)$ is higher than that of the fillet $\left(4.9{ }^{\circ} \mathrm{C} / \mathrm{s}\right.$, point 4$)$ and rolling surface $\left(4.5^{\circ} \mathrm{C} / \mathrm{s}\right.$, point 2$)$.

Here the action of induced current in the rail head is appeared, which passes across the rolling surface and along the side edges, closer to the rail neck. The close values of heating rate in points 1,2 and 3 of rail head are predetermined

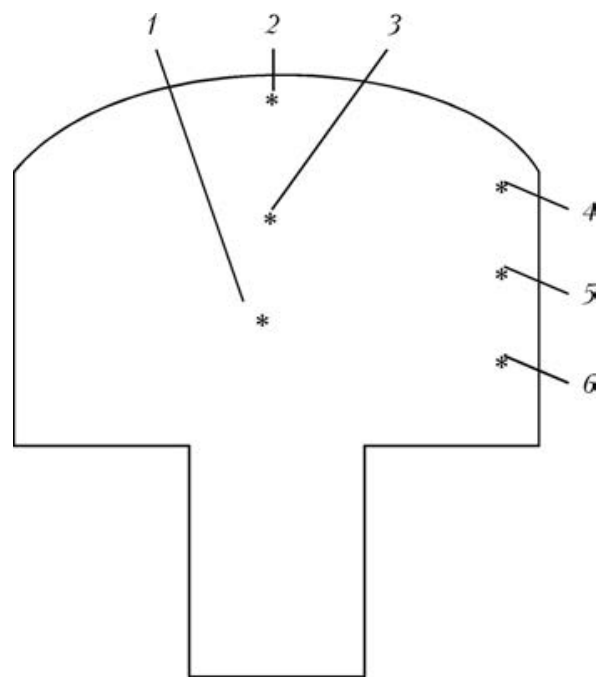

Figure 2. Scheme of positioning of thermal electric transducers in points $1-6$ of cross section of rail head: along the axis of symmetry of rail at depth of 20 (1), 5 (2) and 13 (3) $\mathrm{mm}$ from the rolling surface; at depth of $5 \mathrm{~mm}$, respectively, along the fillet (4), along the centre of side edges (5) and in the lower part of side edges (6) 

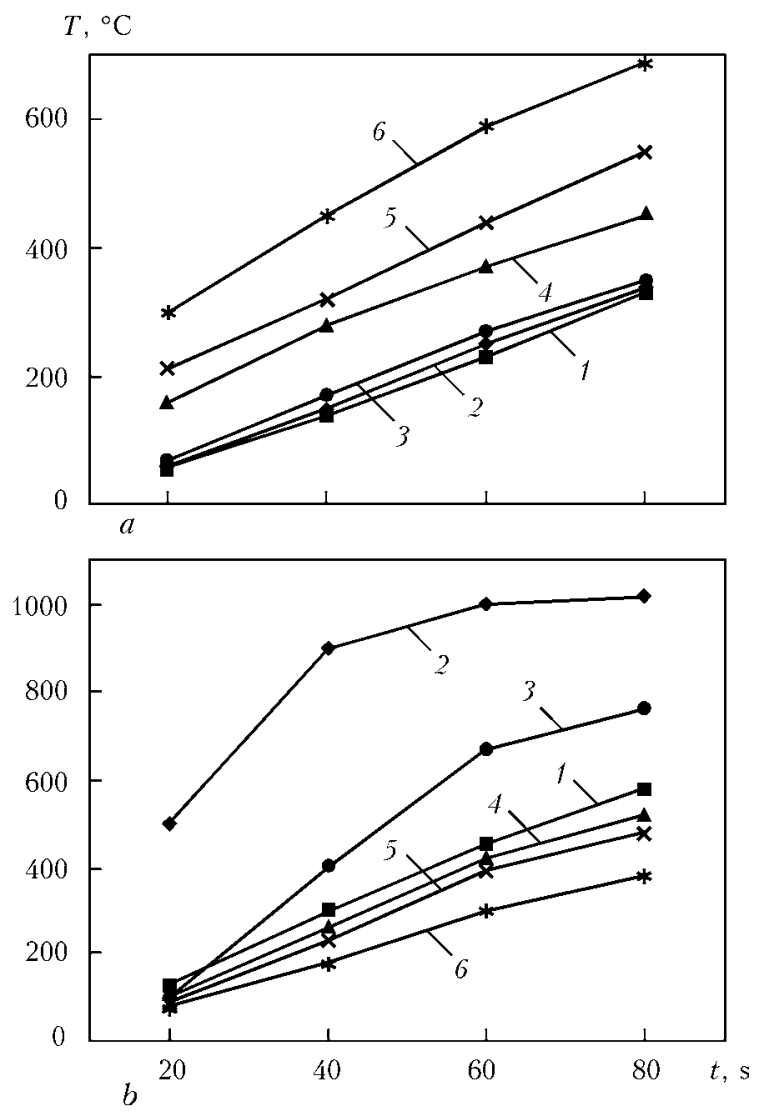

Figure 3. Temporary dependencies of temperature of heating in points $1-6$ of rail head: $a-$ inductor $1 ; b-$ inductor 2 (main magnetic core)

by spreading of temperature field from the side edges to head centre. Within $80 \mathrm{~s}$ of heating (Figure 4) temperature of the lower part of side edges $\left(690^{\circ} \mathrm{C}\right.$, point 6$)$ is higher than that of the fillet $\left(450{ }^{\circ} \mathrm{C}\right.$, point 4$)$ and rolling surface $\left(340{ }^{\circ} \mathrm{C}\right.$, point 2$)$.

During heating of rail head using inductor 2, in design of which the main magnetic core was used, induced current passes along the rolling surface, across the rolling surface and along the side edges. It results in sharp increase of rates of heating in points 1,2 and 3 of rail head (see Figure $3, b$ ) till the moment of reaching of Curie point (about $750{ }^{\circ} \mathrm{C}$ ). In point 2 of rolling surface the rate of heating is $20^{\circ} \mathrm{C} / \mathrm{s}$. The rate of heating of fillet increased $\left(7^{\circ} \mathrm{C} / \mathrm{s}\right.$, point 4$)$, but it decreased in the lower part of side edges $\left(4.2^{\circ} \mathrm{C} / \mathrm{s}\right.$, point 6 ). After $80 \mathrm{~s}$ of heating (see Figure 4), the temperature of rolling surface amounted to 1020 (point 2), of fillet - 520 (point 4) and of side edges $-480{ }^{\circ} \mathrm{C}$ (point 5). The heating temperature at depth of $13 \mathrm{~mm}$ from the rolling surface reached $760{ }^{\circ} \mathrm{C}$ (point 3), and at the depth of $20 \mathrm{~mm}-580{ }^{\circ} \mathrm{C}$ (point 1). The gradient of temperatures at depth of 5-20 $\mathrm{mm}$ from the rolling surface is $260{ }^{\circ} \mathrm{C}$ (points 2 and 3 ). The application of additional magnetic cores in the design of inductor 2 resulted in leveling of heating of the fillet (point 4), side edges (point 5) and

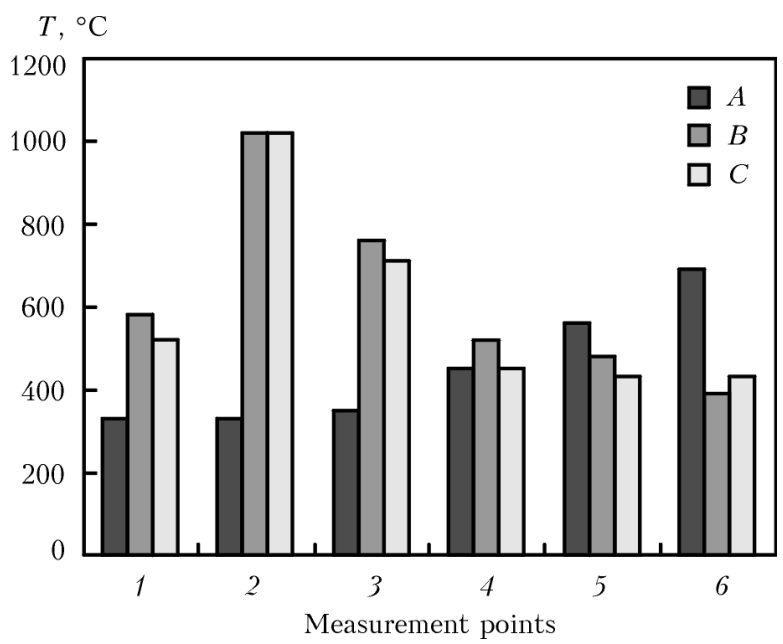

Figure 4. Finite values of temperature in points $1-6$ of rail head through $80 \mathrm{~s}$ of heating: $A-$ inductor $1 ; B-$ inductor 2 (main magnetic core); $C$ - inductor 2 (main and additional magnetic cores)

lower part of side edges. The temperature in those points was $430-450{ }^{\circ} \mathrm{C}$.

\section{Conclusions}

1. To reach the primary heating of rolling surface, as compared to the side edges of rail head, and considerable decrease of capacity of power source is possible by the design of inductor where windings of inductive wire are positioned across the rolling surface, along the rolling surface and along the lower part of side edges, and magnetic core embraces the part of windings of inductive wire over the rolling surface.

2. Application of additional magnetic cores embracing the part of windings of induced current along the side edges of rail head, results in leveling of heating of the fillet, side edges and lower part of side edges.

3 . The carried out investigations allow recommending the design of inductor for application in one of the sections of RHM with the purpose of primary heating of rolling surface as compared to the side edges.

1. Nesterov, D.K. Sapozhkov, V.E., Levchenko, N.F. et al. (1990) Heat treatment of rail steel using the induction heating. Metallovedenie $i$ Term. Obrab. Metallov, 8, 30-34.

2. Golovin, G.F., Zimin, N.V. (1979) Technology of heat treatment of metals using the induction heating. Leningrad: Mashinostroenie.

3. Firstov, S.O., Trotsan, A.P., Kaverinsky, V.V. et al. Method of heat treatment of rails. 'Pat. 76555 Ukraine. Int. Cl. S21D 9/04. Publ. 10.01.2013.

4. Chervinsky, V.I., Shevchenko, V.G. (2010) Application of induction heating in manufacturing and strengthening of products designed for railway transport. Indukts. Nagrev, 4, 18-20.

5. Taras, P., Fireteanu, B. (2010) Inductors for continuous induction heating of rails. Ibid., 4, 21-26.

6. Slukhotsky, A.E., Ryskin, S.G. (1974) Inductors for induction heating. Leningrad: Energiya.

Received 12.01.2015 